\title{
Mutilación genital femenina en Madrid: Migración, contexto y acogida
}

\author{
Pilar Sánchez Boza ${ }^{1, *}$, Paz Núñez Martí ${ }^{2}$ \\ 1 Enfermera especialista en ginecología y obstetricia del Hospital General Universitario Gregorio Marañón; \\ ORCID id: https://orcid.org/0000-0002-7303-2463 \\ 2 Doctora en Arquitectura, profesora de la Universidad de Alcalá; ORCID id: https://orcid.org/0000-0002- \\ 9986-0216 \\ * Autor correspondencia: psboza@gmail.com
}

DOI: https://doi.org/10.37536/RIECS.2021.6.1.257

Recibido: 14/05/2021; Aceptado: 24/05/2021; Publicado: 31/05/2021

Resumen: En 2018 los datos del padrón municipal de la Comunidad de Madrid desvelaron que, la cantidad de supervivientes a la mutilación genital femenina (MGF) se eleva aproximadamente a 7.300 mujeres originarias de Nigeria, Senegal, Camerún y Guinea, asimismo, cerca de 340 menores están en riesgo de sufrir este tipo de maltrato. Además, los últimos estudios muestran que esta práctica se extiende a más de 90 países en todo el mundo. Para dar acogida a las supervivientes de la MGF la Comunidad de Madrid creó en 2013 “La Red de Prevención de Mutilación Genital Femenina" y además desde el 2017 está en vigor la "Guía de Actuaciones Sanitarias para la Prevención de la Mutilación Genital Femenina en la Comunidad de Madrid", que permite un trabajo multidisciplinar de forma sistematizada, si bien la investigación revela que existe una brecha asistencial en la salud sexual de estas mujeres.

Palabras Clave: Mutilación, Genital, Femenina, Derechos, Humanos, Mujer.

\begin{abstract}
In 2018, data from the municipal standard of the Community of Madrid revealed that the number of survivors of female genital mutilation (FGM) rises to approximately 7,300 women who come from Nigeria, Senegal, Cameroon and Guinea, and nearly 340 children are at risk of this type of abuse. In addition, the latest studies show that this practice extends to more than 90 countries worldwide. To welcome the survivors of FGM, the Community of Madrid created in 2013 "The Network for the Prevention of Female Genital Mutilation" and also since 2017 the "Guide to Health Actions for the Prevention of Female Genital Mutilation in the Community of Madrid" has been in force, which allows multidisciplinary work in a systematized way, although research reveals that there is a healthcare gap in the sexual health of these women.
\end{abstract}

Key words: Mutilation, Genital, Female, Rights, Human, Woman.

\section{Introducción}

La OMS considera que la MGF "comprende todos los procedimientos consistentes en la resección parcial o total de los genitales externos femeninos, así como otras lesiones de los órganos genitales femeninos por motivos no médicos" [3]. La legislación a nivel global considera que la MGF viola los derechos de la mujer puesto que favorece una participación de la mujer desigual en la sociedad, controlando la sexualidad de la mujer e imponiendo cánones de género humillantes. Las consecuencias que produce a largo plazo impiden que las mujeres puedan participar de forma plena en la sociedad [4]. 
Actualmente, la MGF, está evidenciada en 28 países de África, en países de Oriente Medio, Asia y en comunidades aisladas de Centroamérica y Suramérica [5]. La justificación de esta práctica se encuentra en la creencia de que la niña conservará así su virginidad y castidad, asegurándose el matrimonio, un futuro próspero y la aceptación social [5]. Además, en 2015 UNICEF elaboró un informe sobre la MGF, destacando el aumento de la práctica medicalizada, siendo Egipto el país predominante, donde un $75 \%$ de la MGF se realiza en un entorno sanitario [6].

Gracias al padrón municipal del 2018 de la Comunidad de Madrid sabemos que más de 7000 mujeres que viven en la Comunidad de Madrid provienen de un país donde la práctica de la MGF está arraigada como son Guinea, Camerún, Nigeria o Senegal (ver tabla I), además cerca de 350 menores pueden sufrir MGF en la Comunidad Autónoma de Madrid [1].

Tabla I Porcentaje la práctica de la mgf en países subsahariano [7]

\begin{tabular}{|l|c|}
\hline País de origen & Prevalencia de la MGF. \\
\hline Guinea-Conakri & $97 \%$ \\
\hline Nigeria & $25 \%$ \\
\hline Senegal & $25 \%$ \\
\hline Camerún & $1 \%$ \\
\hline
\end{tabular}

Los datos evidencian la necesidad urgente de una acogida eficaz para todas las supervivientes o mujeres en riesgo de sufrir MGF, ampliando la actuación socio-sanitaria para solventar las brechas asistenciales que aún quedan por cubrir.

El objetivo general de este estudio es visibilizar las carencias de la acogida sanitaria de las supervivientes de la MGF en la Comunidad de Madrid desde el 2018 en adelante, y como objetivo específico ha sido necesario conocer los flujos migratorios, cultura, situación personal y el enfoque multidisciplinar aplicado a cada mujer con MGF en la Comunidad de Madrid desde 2018 en adelante, siendo una posible solución la implantación de un taller de educación para la salud sexual destinado a las supervivientes/mujeres en riesgo de MGF y a sus acompañantes, que se implementará en el centro de salud de Lavapiés a finales de 2021.

\section{Material y Métodos}

Para la elaboración de este artículo hemos realizado una búsqueda bibliográfica basada en informes de ONGs y organismos internacionales, protocolos y normativas, planes de acción, convenios y tratados internacionales, guías de prevención, además de diversas noticias de prensa, tanto nacionales como internacionales relacionados con la MGF. Además, este trabajo se sustenta en numerosos testimonios de supervivientes, mujeres en riesgo de sufrir MGF y sanitarios que trabajan directamente con estas mujeres, con el objetivo de retratar una realidad cercana y personal.

Indicar que las ilustraciones son de elaboración propia, en las cuales se han empleado colores inclusivos y trazos sencillos con el fin de que sean de fácil recreación, de cara a un futuro uso formativo ya sea por las mediadoras, por las supervivientes o por el propio profesional sanitario. 


\section{Resultados}

\subsection{Aspectos generales de la MGF}

\subsubsection{Orígenes y justificación}

El origen de la MGF es desconocido, pero existe constancia en el antiguo Egipto, la Arabia preislámica, la Rusia Zarista y la antigua Roma [8,9]. En 1930 la ablación de clítoris se realizaba en Europa y Estados Unidos como medida terapéutica para la clitoromegalia, la redundancia, la histeria, el lesbianismo y la erotomanía [10]. Actualmente, la MGF, está evidenciada en 28 países de África, en países de Oriente Medio, Asia y en comunidades aisladas de Centroamérica y Suramérica [5].

La MGF se trata de una tradición que concede identidad de género y de etnia a las mujeres/niñas. Se ejecuta creyendo que facilita la preservación de la virginidad, fomenta la fidelidad e incrementa las posibilidades nupciales, asimismo está relacionado con cánones de belleza femenina, incluso en algunas tribus de Sudamérica se practica para evitar la clitoromegalia [11].

A nivel de salud, se cree que una mujer con MGF es más higiénica, puesto que ayuda a gozar de buena salud, fecundidad (evitando el aborto y los fetos cruz) y además facilita el parto eutócico.

En algunas comunidades se considera un ritual de paso a la edad adulta, suponiendo una iniciación de las niñas a la madurez en el cual se les transmite las enseñanzas ancestrales. Otras veces, se realiza como mandato religioso, siendo la MGF una práctica entre [12]:

- Cristianas coptas: mujeres originarias de Egipto, aunque en 2017 la Iglesia Copta Ortodoxa inició entre los fieles una campaña de sensibilización contra la práctica de la infibulación y la mutilación genital femenina. El origen de la infibulación está ligado al Antiguo Egipto, llamándose "infibulación faraónica" (Khitan a fira’uni). También se encuentra esta práctica en Etiopía y Sudán.

- Judías falashas: Mujeres Etíopes.

- Practica preislámica calificada como Sunna (tradición o recomendación) aunque no la indica el islam.

\subsubsection{Tipos y características de la MGF.}

La OMS considera que la MGF "comprende todos los procedimientos consistentes en la resección parcial o total de los genitales externos femeninos, así como otras lesiones de los órganos genitales femeninos por motivos no médicos" [3]. A nivel internacional esta práctica se considera una violación de los derechos humanos.

Según Ayuda en Acción, la OMS, la AEGO, Médicos del Mundo, la FIGO, la semFYC, etc. la MGF se clasifica en 4 subtipos según las zonas afectadas: (ver tabla II) 
Tabla II Tipos de mutilación genital femenina ${ }^{1}$

\begin{tabular}{|c|c|c|}
\hline $\begin{array}{l}\text { TIPO I. CLITORIDECTOMÍA: } \\
\text { Se realiza la extirpación total del } \\
\text { clítoris y parte del prepucio. }\end{array}$ & & $\begin{array}{l}\text { La zona en rojo hace referencia al tejido } \\
\text { extirpado mediante corte representado por } \\
\text { unas tijeras. }\end{array}$ \\
\hline $\begin{array}{l}\text { TIPO II. CLITORIDECTOMÍA Y } \\
\text { EXTIRPACIÓN PARCIAL DE LOS } \\
\text { LABIOS MENORES: } \\
\text { Eliminación del clítoris y parte de los } \\
\text { labios menores. }\end{array}$ & & $\begin{array}{l}\text { La zona en rojo hace referencia al tejido } \\
\text { extirpado mediante corte representado por } \\
\text { unas tijeras. }\end{array}$ \\
\hline $\begin{array}{l}\text { TIPO III. INFUNDIBULACIÓN: } \\
\text { Este tipo de MGF se realiza en dos } \\
\text { pasos: } \\
1^{\text {o }} \text { Se extirpa el clítoris y los labios } \\
\text { menores. (MGF tipo II. Ver dibujo } \\
2 \text { ) } \\
2^{\text {o }} \text { Se hace incisión en labios } \\
\text { mayores y se aproximan mediante } \\
\text { puntos de sutura por encima de la } \\
\text { uretra y de la apertura vaginal, lo } \\
\text { que se conoce como infibulación. } \\
\text { Existen dos tipos e infibulación: }\end{array}$ & $\begin{array}{l}\text { TOTAL. (Para la } \\
\text { AEGO esta sería la } \\
\text { MGF tipo IV) }\end{array}$ & $\begin{array}{l}\text { La zona en rojo hace referencia al tejido } \\
\text { extirpado mediante corte, las líneas } \\
\text { transversales al corte y la aguja representan } \\
\text { el cierre mediante sutura, dejando un } \\
\text { orificio de tamaño moderado de color negro. } \\
\text { La zona en rojo hace referencia al tejido } \\
\text { extirpado mediante corte, las líneas } \\
\text { transversales al corte y la aguja representan } \\
\text { el cierre mediante sutura, dejando un } \\
\text { orificio de tamaño moderado de color negro }\end{array}$ \\
\hline $\begin{array}{l}\text { TIPO IV. OTROS: } \\
\text { Comprende todos los demás } \\
\text { procedimientos dañinos de los } \\
\text { genitales externos con fines no } \\
\text { médicos, tales como perforar, corta, } \\
\text { lacerar, suturar o cauterizar los } \\
\text { órganos sexuales externos. }\end{array}$ & & $\begin{array}{l}\text { La zona dibuja en violeta hace referencia al } \\
\text { tejido susceptible de ser dañado y a la } \\
\text { derecha del dibujo se representan los } \\
\text { múltiples objetos con los que se puede } \\
\text { mutilar (Fuego, pendientes, atravesar } \\
\text { genitales con espinas de pescado, etc.) }\end{array}$ \\
\hline
\end{tabular}

\subsubsection{Procedimiento}

La MGF se realiza entre los 4-14 años, dependiendo de la zona geográfica o religión se puede vivir como una fiesta en la que los familiares y amigos obsequian a la niña con dinero, oro y ropa, mientras que en otras situaciones las niñas son secuestradas en medio de la noche para mutilarlas. Las personas que realizan la circuncisión suelen ser mujeres sin formación médica, en unos casos lo

${ }^{1}$ Recurso gráfico de elaboración propia de carácter inclusivo, con los que se trabajará en los Talleres de Salud Sexual y Reproductiva para Mujeres Supervivientes de la MGF Fuente AEGO [13], UNAF y Ayuda en Acción [14] 
practica la partera tradicional de la zona, en otros una de las personas mayores/sabias del pueblo, matronas, dayas o incluso personal sanitario. Los instrumentos utilizados suelen ser cuchillos, navajas, tijeras, etc. que rara vez se esterilizan, asimismo el uso de anestesia y antibioterapia es inusual. La hemostasia se asegura mediante suturas catgut, espinas o brebajes adhesivos caseros como azúcar, huevo o excrementos de animales. Para la realización del procedimiento se atan los tobillos de la niña a los muslos y se las mantiene en esta postura guardando cama durante una semana.

Otra corriente de esta práctica es la MGF medicalizada, es decir la mutilación se lleva a cabo en un entorno sanitario (hospital o centro de salud) y por profesionales de la salud que emplean medicamentos y utensilios sanitarios que cumplen las medidas de asepsia, con la finalidad de disminuir la incidencia en hemorragias o infecciones, no obstante se ha corroborado que la reconstrucción posterior del clítoris es menos probable, ya que al tener conocimientos en anatomía llegan a extirpar la totalidad del órgano.

En 2010, la OMS, junto con las Naciones Unidas y otros organismos internacionales crearon la Global strategy to stop health care providers from performing female genital mutilation [15], para poner fin a la MGF medicalizada, por otro lado la OMS estableció que "cualquier forma de MGF no debe ser practicada por profesionales sanitarios en ningún lugar, incluidos los hospitales $u$ otros establecimientos sanitarios" [16], siendo un acto condenado ya en 1993 [17] por la Asociación Médica Mundial, yendo en contra del principio de No Maleficencia, que debe cumplir de forma prioritaria cualquier sanitario. En 2013 UNICEF elaboró un informe acerca de la MGF, destacando el aumento de la práctica medicalizada [18].

\subsubsection{Complicaciones y resultados}

- $\quad$ Físicos: (ver Tabla III)

Tabla III Complicaciones y resultados de la mutilación genital femenina

\begin{tabular}{|c|c|c|c|}
\hline $\begin{array}{l}\text { COMPLICACIONES } \\
\text { PERIPROCEDIMIENTO }\end{array}$ & $\begin{array}{l}\text { PROBLEMAS } \\
\text { GINECOLÓGICOS A LARGO } \\
\text { PLAZO }\end{array}$ & \multicolumn{2}{|c|}{ PROBLEMAS OBSTÉTRICOS } \\
\hline \multirow{3}{*}{$\begin{array}{l}\text { - Intraquirúrgico: falta } \\
\text { de anestesia y la } \\
\text { resistencia de la niña. } \\
\text { - Complicaciones } \\
\text { tempranas: } \\
\text { hemorragia, } \\
\text { infección/sepsis, } \\
\text { oliguria [19]. }\end{array}$} & $\begin{array}{l}\text { Las supervivientes con MGF } \\
\text { tipo II y III tienen más } \\
\text { complicaciones que las de tipo I } \\
\text { y IV }\end{array}$ & $\begin{array}{l}\text { Seguimiento del } \\
\text { trabajo de parto }\end{array}$ & $\begin{array}{l}\text { Resultado del } \\
\text { embarazo }\end{array}$ \\
\hline & $\begin{array}{l}\text { - Dismenorrea, la dispareunia, } \\
\text { infecciones vaginales } \\
\text { crónicas. } \\
\text { - Alteraciones en la micción: } \\
\text { obstrucciones del meato y } \\
\text { estenosis uretral, carcinitis, } \\
\text { cálculos urinarios e ITU } \\
\text { crónicas [20,21,22]. }\end{array}$ & \multirow[t]{2}{*}{$\begin{array}{l}\text { - El neointroito } \\
\text { estrecho dificulta } \\
\text { la valoración de } \\
\text { la dilatación, } \\
\text { siendo doloroso } \\
\text { para la mujer. }\end{array}$} & \multirow{2}{*}{$\begin{array}{l}\text { Las mujeres con MGF } \\
\text { II y III, pero no con } \\
\text { MGF I, tienen mayor } \\
\text { riesgo de cesárea, } \\
\text { hemorragia posparto } \\
\text { y estancia } \\
\text { hospitalaria } \\
\text { prolongada y los } \\
\text { neonatos tienen } \\
\text { mayor riesgo de } \\
\text { requerir reanimación } \\
\text { y de muerte perinatal } \\
\text { [23]. }\end{array}$} \\
\hline & $\begin{array}{l}\text { - Alteraciones en la } \\
\text { cicatrización: fibrosis, } \\
\text { queloides, quistes } \\
\text { epidérmicos, abscesos } \\
\text { vulvares y fusión total/parcial } \\
\text { de labios menores/mayores, } \\
\text { hematometra o hematocolpos, } \\
\text { infección vaginal crónica y } \\
\text { neuromas }[24,25] \text {. }\end{array}$ & & \\
\hline
\end{tabular}




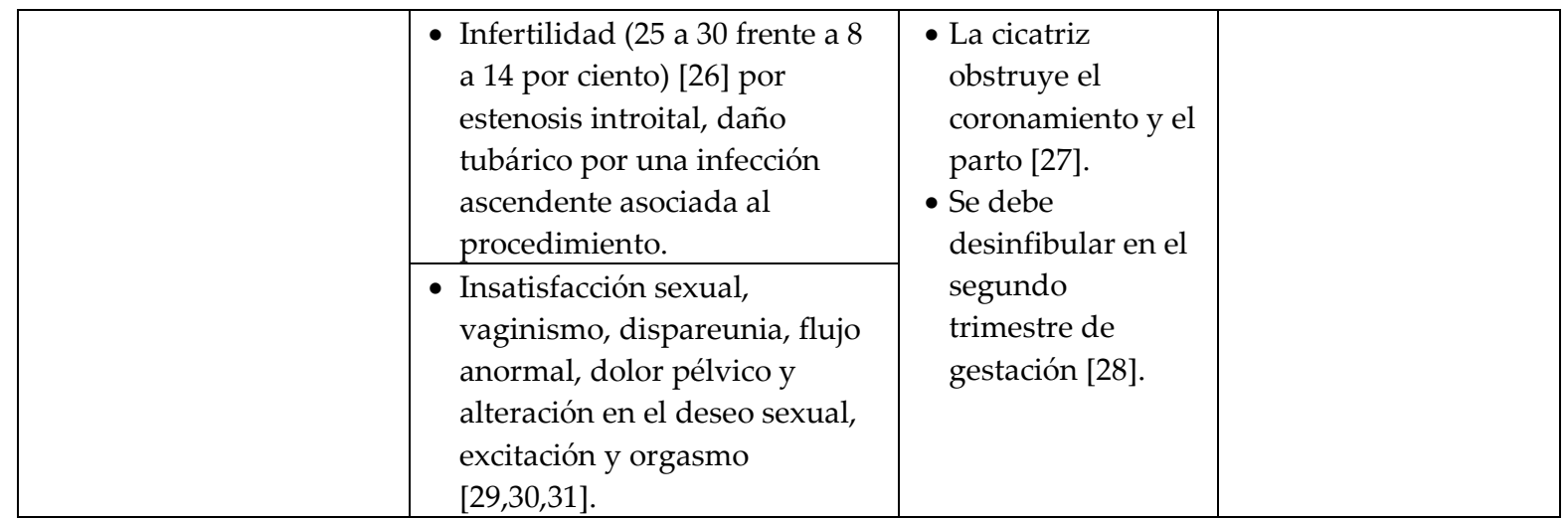

\section{- Psicosociales:}

Las secuelas psicológicas están causadas por los sentimientos contradictorios provocados por la sociedad a la que pertenecen, las supervivientes sienten miedo a ser excluidas por la gente de su propio círculo si no se someten a la MGF. En estas culturas, además si no están mutiladas es difícil encontrar marido y con ello un sustento económico y desenvoltura social, manifestándose psicológicamente con depresión y ansiedad [31]. Además, la MGF desencadena pérdida de confianza en los cuidadores (padres, abuelos...), generando sentimientos encontrados o labilidad emocional.

Con respecto a la relación de pareja, suelen predominar disfunciones sexuales como el vaginismo o la anorgasmia (ver tabla 3.1.4.1.) que desencadenan conflictos de pareja que pueden acabar en divorcio. Además, se ha descrito un síndrome específico denominado "síndrome de la ansiedad-depresión enfocada genitalmente"[32] caracterizado por una constante preocupación de las supervivientes a la MGF, sobre el estado de sus genitales y su fertilidad.

En el caso de las mujeres que han emigrado a países donde no se practica, los problemas se encuentran en la diferencia cultural, ya que en el país de acogida puede estar la MGF incluso penado por la ley. Este hecho genera, hacia su agrupación cultural, conflictos de identidad y lealtad, alimentados por creencias de traición, confusión, y sentimientos de humillación, anulación y vergüenza. El resultado son problemas de exclusión social y de autoestima [31, 32].

Una mujer con baja autoestima, apartada de la sociedad en un país desconocido, tiene menos herramientas y habilidades para crear nuevos círculos sociales, y encontrar un trabajo digno del que obtenga un sueldo para poder cubrir sus necesidades básicas de la vida diaria y las de su descendencia, como son la alimentación, el aseo, la educación o una vivienda digna. Lo cual convierte a la mujer con MGF, incluso a sus hijos, en personas vulnerables a la pobreza o la enfermedad.

\subsubsection{Enfoque multidisciplinar para erradicar la práctica: legislativo vs opinión social.}

Se observa que el año de adhesión de leyes o decretos en contra de la MGF y la opinión social son los dos ítems más importantes para disminuir esta práctica. A continuación, en la tabla IV se asocia año de adhesión a leyes o decretos en contra de la MGF vs países con mayor incidencia en el año 2018 de MGF en población de 0 a 14 años y de 15 a 49 años, además, se incluyen datos significativos sobre la opinión social de mujeres y hombres de 15 a 49 años sobre la abolición de esta práctica. Como se puede observar muchas casillas se muestran sin datos, esto revela que sigue siendo un tema de difícil abordaje y sobre el cual se debe seguir trabajando. 
Tabla IV Países y el año de adhesión de leyes o decretos en contra de la MGF vs mujeres mutiladas

$[15,33]$

\begin{tabular}{|c|c|c|c|c|c|}
\hline \multirow[t]{2}{*}{ Paises } & \multirow{2}{*}{$\begin{array}{c}\text { Año de } \\
\text { adhesión de } \\
\text { leyes o decretos } \\
\text { en contra de la } \\
\text { MGF. }\end{array}$} & \multirow{2}{*}{$\begin{array}{l}\text { Incidencia } \\
\text { de MGF en } \\
\text { mujeres de } \\
0 \text { a } 15 \text { años } \\
(2010-2018)\end{array}$} & \multirow{2}{*}{$\begin{array}{c}\text { Incidencia } \\
\text { de MGF en } \\
\text { mujeres de } \\
15 \text { a } 45 \text { años } \\
\text { (2018) }\end{array}$} & \multicolumn{2}{|c|}{$\begin{array}{c}\text { Porcentaje de personas que piensan } \\
\text { que se debe eliminar la MGF }\end{array}$} \\
\hline & & & & $\begin{array}{c}\text { Mujeres y } \\
\text { niñas de } 15 \text { a } \\
49 \text { años. }\end{array}$ & $\begin{array}{l}\text { Hombres y niños de } \\
15 \text { a } 49 \text { años. }\end{array}$ \\
\hline Burkina Faso & 1996 & $13 \%$ & $76 \%$ & Sin datos & Sin datos \\
\hline $\begin{array}{l}\text { República } \\
\text { centroafricana }\end{array}$ & 1996 & $1 \%$ & $24 \%$ & Sin datos & Sin datos \\
\hline Costa Marfil & 1998 & $10 \%$ & $37 \%$ & Sin datos & Sin datos \\
\hline R.U. Tanzania & 1998 & 0,4 & $10 \%$ & $95 \%(2018)$ & Sin datos \\
\hline Togo & 1998 & $0,3 \%$ & $3 \%$ & Sin datos & Sin datos \\
\hline Nigeria & $\begin{array}{l}\text { 1999-2006 } \\
\text { (algunos } \\
\text { estados) }\end{array}$ & $13 \%$ & $19 \%$ & Sin datos & Sin datos \\
\hline Senegal & 1999 & $14 \%$ & $24 \%$ & $80,9 \%(2017)$ & $78,8 \%$ (2017) \\
\hline Guinea & 2000 & $39 \%$ & $95 \%$ & $62,1 \%(2018)$ & $32,6 \%(2018)$ \\
\hline Yemen & 2001 & $15 \%$ & $19 \%$ & Sin datos & Sin datos \\
\hline Benin & 2003 & $9 \%$ & $0,1 \%$ & Sin datos & Sin datos \\
\hline Chad & 2003 & $10 \%$ & $38 \%$ & Sin datos & Sin datos \\
\hline Niger & 2003 & Sin datos & $2 \%$ & Sin datos & Sin datos \\
\hline Etiopia & 2004 & $16 \%$ & $65 \%$ & $79,3 \%(2016)$ & $86,7 \%$ (2016) \\
\hline Mauritania & 2005 & $51 \%$ & $67 \%$ & Sin datos & Sin datos \\
\hline Eritrea & 2007 & $33 \%$ & $83 \%$ & Sin datos & Sin datos \\
\hline Ghana & 2007 & $1 \%$ & $4 \%$ & Sin datos & Sin datos \\
\hline Egipto & 2008 & $14 \%$ & $87 \%$ & Sin datos & Sin datos \\
\hline Sudán & $\begin{array}{l}\text { 2008-2009 } \\
\text { (algunos } \\
\text { estados) }\end{array}$ & $30 \%$ & $87 \%$ & Sin datos & Sin datos \\
\hline Djibouti & 2009 & $43 \%$ & $94 \%$ & Sin datos & Sin datos \\
\hline Uganda & 2010 & $1 \%$ & $1 \%$ & Sin datos & Sin datos \\
\hline $\begin{array}{l}\text { Guinea- } \\
\text { Bissau }\end{array}$ & 2011 & $29 \%$ & $45 \%$ & Sin datos & Sin datos \\
\hline Irak & $\begin{array}{l}2011 \text { en el } \\
\text { Kurdistan }\end{array}$ & $1 \%$ & $7 \%$ & $93,6 \%(2018)$ & Sin datos \\
\hline Kenya & 2011 & $3 \%$ & $21 \%$ & Sin datos & Sin datos \\
\hline Somalia & 2012 & Sin datos & $98 \%$ & Sin datos & Sin datos \\
\hline Camerún & $\begin{array}{c}\text { No existe } \\
\text { legislación sobre } \\
\text { MGF }\end{array}$ & Sin datos & $1 \%$ & Sin datos & Sin datos \\
\hline
\end{tabular}




\begin{tabular}{|c|c|c|c|c|c|}
\hline Gambia & $\begin{array}{c}\text { No existe } \\
\text { legislación sobre } \\
\text { MGF }\end{array}$ & $21 \%$ & $77 \%$ & $48,9 \%$ (2018) & Sin datos \\
\hline Liberia & $\begin{array}{c}\text { No existe } \\
\text { legislación sobre } \\
\text { MGF }\end{array}$ & Sin datos & $44 \%$ & Sin datos & Sin datos \\
\hline Mali & $\begin{array}{c}\text { No existe } \\
\text { legislación sobre } \\
\text { MGF }\end{array}$ & $83 \%$ & $89 \%$ & $17,5 \%(2018)$ & $12,6 \%$ (2018) \\
\hline Sierra Leona & $\begin{array}{c}\text { No existe } \\
\text { legislación sobre } \\
\text { MGF }\end{array}$ & $8 \%$ & $86 \%$ & $26,8 \%(2017)$ & Sin datos \\
\hline Cotê D'Ivoire & $\begin{array}{c}\text { No existe } \\
\text { legislación sobre } \\
\text { MGF }\end{array}$ & $0,1 \%$ & $37 \%$ & $79,4 \%$ (2017) & Sin datos \\
\hline Maldivas & $\begin{array}{c}\text { No existe } \\
\text { legislación sobre } \\
\text { MGF }\end{array}$ & $1 \%$ & $13 \%$ & $65,9 \%(2017)$ & Sin datos \\
\hline
\end{tabular}

\subsection{La MGF en Madrid}

3.2.1. Migración: mujeres de la Comunidad de Madrid procedentes de países donde se practica la mutilación genital femenina.

En 2018 los datos del padrón municipal de la Comunidad de Madrid revelaron que, la cantidad de supervivientes a la MGF se "eleva a 7.295 mujeres proviniendo fundamentalmente de Nigeria, Senegal, Camerún y Guinea. Además, restudios recientes revelan que esta práctica se extiende a 92 países a lo largo del mundo entre los que se encuentran Colombia, Rusia o Indonesia, no obstante, los datos no son estadísticamente significativos. Por último, cabe destacar que actualmente 335 menores están en riesgo de sufrir la MGF en la comunidad de Madrid", según el último análisis elaborado por la Fundación Wassu - UAB, con la participación de la Delegación del Gobierno contra la Violencia de Género [1].

En la siguiente Tabla V se puede observar la distribución de menores de 15 años y mujeres adultas que viven en Madrid con relación al país de origen según la prevalencia de la MGF. Además, se les brinda especial importancia a las mujeres nigerianas que el colectivo más numeroso en Madrid (3.731) seguidas de las de Senegal (802), siendo la prevalencia de la MGF en ambos países del 25\%, además no nos debemos olvidar de las mujeres procedentes de Egipto, Guinea Conakri y Mali, por su elevada prevalencia en la práctica de la MGF [2] en estos países. Además, las mujeres originarias de estos países son muy jóvenes, el 26,7\% (1.922) son menores de 15 años y un 54,94\% (1056) son menores de 5 años [7]. 
Tabla V Mujeres originarias de países donde se practica la FGM que viven en la Comunidad Autónoma de Madrid en relación al país de procedencia relacionado con la prevalencia de la MGF [7]

\begin{tabular}{|l|c|c|c|}
\hline País de origen & $\begin{array}{c}\text { Prevalencia de } \\
\text { la MGF. }\end{array}$ & $\begin{array}{c}\text { Población total de mujeres en } \\
\text { Madrid. }\end{array}$ & Mujeres <15 años. \\
\hline Nigeria & $25 \%$ & 3721 & 1077 \\
\hline Senegal & $25 \%$ & 802 & 100 \\
\hline Camerún & $1 \%$ & 423 & 109 \\
\hline Guinea-Conakri & $97 \%$ & 354 & 94 \\
\hline Mali & $89 \%$ & 222 & 53 \\
\hline Egipto & $87 \%$ & 199 & 49 \\
\hline Ganha & $4 \%$ & 186 & 40 \\
\hline Costa de Marfil & $38 \%$ & 175 & 26 \\
\hline Iraq & $8 \%$ & 171 & 42 \\
\hline Guinea-Bissau & $45 \%$ & 165 & 14 \\
\hline Indonesia & $49 \%$ & 159 & 28 \\
\hline Etiopía & $74 \%$ & 138 & 7 \\
\hline Kenia & $21 \%$ & 114 & 17 \\
\hline Mauritania & $69 \%$ & 68 & 57 \\
\hline Resto & & 297 & 1922 \\
\hline Total & & 7204 & \\
\hline
\end{tabular}

\subsubsection{Marco legislativo de la Comunidad de Madrid sobre la MGF.}

Concretamente en nuestra comunidad, la "Ley de la Comunidad de Madrid 5/2005, de 29 de septiembre, de Violencia de Género" [34], se aplica a cualquier manifestación de la MGF:

- Artículo 7.4 dispone que, "a efectos de la detección y prevención de situaciones de riesgo de mutilación genital, la Comunidad de Madrid elaborará, en colaboración con los municipios de su ámbito territorial, un protocolo específico de actuación en esta materia" [34].

- Artículo 29 dispone que "la Comunidad de Madrid ejercerá la acción popular en los procedimientos penales por causa de mutilación genital" [34].

\subsubsection{Contexto de la mutilación genital femenina en Madrid.}

En el padrón municipal el 2018, se observa que aumentan de 7204 (datos del 2015) a 7.295 [35, 36] las mujeres que proceden de países donde se practica la MGF, siendo principalmente de países de África subsahariana, además esta población se agrupa de forma irregular en la Comunidad de Madrid, entre paréntesis se especifican datos exactos de algunas zonas revelados por el padrón municipal del 2018:

- En el área metropolitana se encuentra en Madrid ciudad (2416 mujeres con MGF), Alcobendas, Tres Cantos, Torrejón de Ardoz (548 mujeres con MGF), Alcalá de Henares (546 mujeres con MGF), Coslada, Pozuelo, Alcorcón, Móstoles, Leganés Getafe Fuenlabrada (1008 mujeres con MGF), Parla (706 mujeres con MGF), Pinto [35].

- En la Comarca sur las mujeres con MGF se asientan principalmente en Valdemoro [35].

- En la Comarca de Las Vegas la supervivientes viven en Ciempozuelos y Aranjuez [35]. 


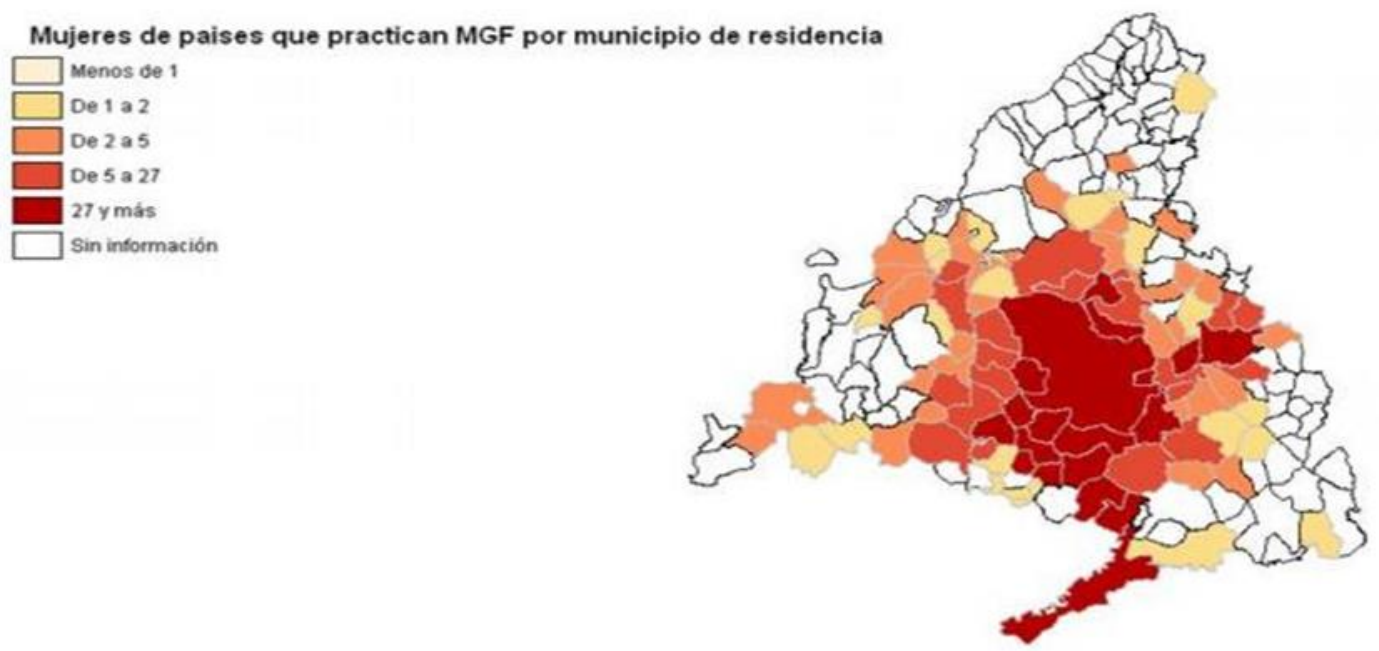

Figura 1 Distribución de mujeres procedentes de países que practican la MGF por municipio de residencia en la Comunidad de Madrid [2] (Fuente datos de Padrón continúo, 2015, UNICEF, 2016. Imagen extraída la de Guía De Actuaciones Sanitarias Frente A La Mutilación Genital Femenina En La Comunidad De Madrid, 2017. Disponible en:

http://www.luaediciones.com/seps/violencia_sexual_infancia/Guia_Actuaciones_sanitarias_MGF_2 017.pdf)

Si nos centramos en Madrid ciudad encontramos de nuevo una distribución irregular de mujeres con MGF o en riesgo de sufrir esta práctica, asentándose mayoritariamente en Puente de Vallecas, Villaverde, Carabanchel, Ciudad Lineal, Latina y Centro.

Mujeres de países que practican MGF por distrito de residencia en la ciudad de Madrid
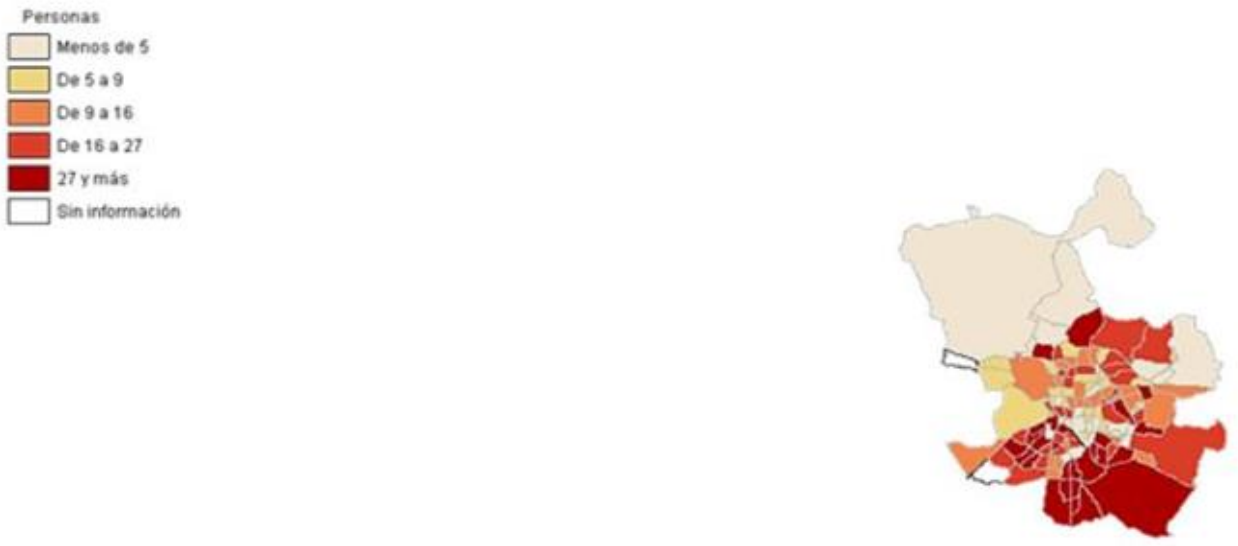

Figura 2 Distribución de mujeres procedentes de países que practican la MGF por barrios y distritos en la ciudad de Madrid (Fuente datos de Padrón continúo, 2015, UNICEF, 2016. Imagen extraída la de Guía De Actuaciones Sanitarias Frente A La Mutilación Genital Femenina En La Comunidad De Madrid, 2017. Disponible en:

http://www.luaediciones.com/seps/violencia_sexual_infancia/Guia_Actuaciones_sanitarias_MGF_2 017.pdf) 
La causa de la agrupación social irregular es la concatenación de una serie de factores económicos, sociales, culturales y sanitarios.

A nivel económico se dan tres situaciones:

- Una minoría de mujeres mutiladas poseen título formativo de su país de origen y se encuentra en situación de regularidad. La convalidación de su formación es un proceso arduo y prolongado en el tiempo, mientras tanto suelen desempeñar trabajos poco o nada cualificados para subsistir.

- Las mujeres supervivientes con papeles, pero sin título formativo, suelen desempeñar trabajos poco o nada cualificados. como son la hostelería, el cuidado de personas dependientes o la asistencia del hogar. En determinadas ocasiones se asientan en barrios de clase socioeconómica alta (Pozuelo, Alcobendas) debido a que trabajan de internas en las casas, hecho que les genera la separación de sus familiares y amigos, trabajando las 24 horas del día, con pocas horas de descanso, sin embargo, cotizan en la seguridad social, tienen acceso a los servicios sanitarios públicos e incluso a la escolarización de sus hijos.

- Por otro lado, nos encontramos con las supervivientes sin papeles, que desempeñan trabajos poco o nada cualificados, con sueldos precarios generalmente pagadas con dinero negro. De nuevo se repiten las profesiones anteriores, a las cuales se les suman la trata de mujeres, la prostitución, trabajar para mafias o la venta de droga. Estas mujeres viven sin acceso a los servicios públicos de sanidad o educación poniendo en peligro su integridad, además no pueden pedir ayuda o denunciar a la justicia española la situación de abuso que viven, por miedo a ser descubiertas como inmigrantes sin papeles y ser devueltas a su país de origen, convirtiéndose en una realidad difícil de salir.

A nivel social las mujeres supervivientes de MGF se asientan en zonas donde la renta per cápita es más baja (menos de 10.000 euros) ya que esa población solo se puede permitir una vivienda a un coste metro cuadrado de los más bajos de la Comunidad de Madrid como son los distritos de Puente de Vallecas, Villaverde, Carabanchel, Ciudad Lineal, Latina y Centro (ver recurso figura 3) y que además lideran los primeros puestos del ranking de vulnerabilidad por distritos en el año 2020 de la Comunidad de Madrid (ver tabla VI) 


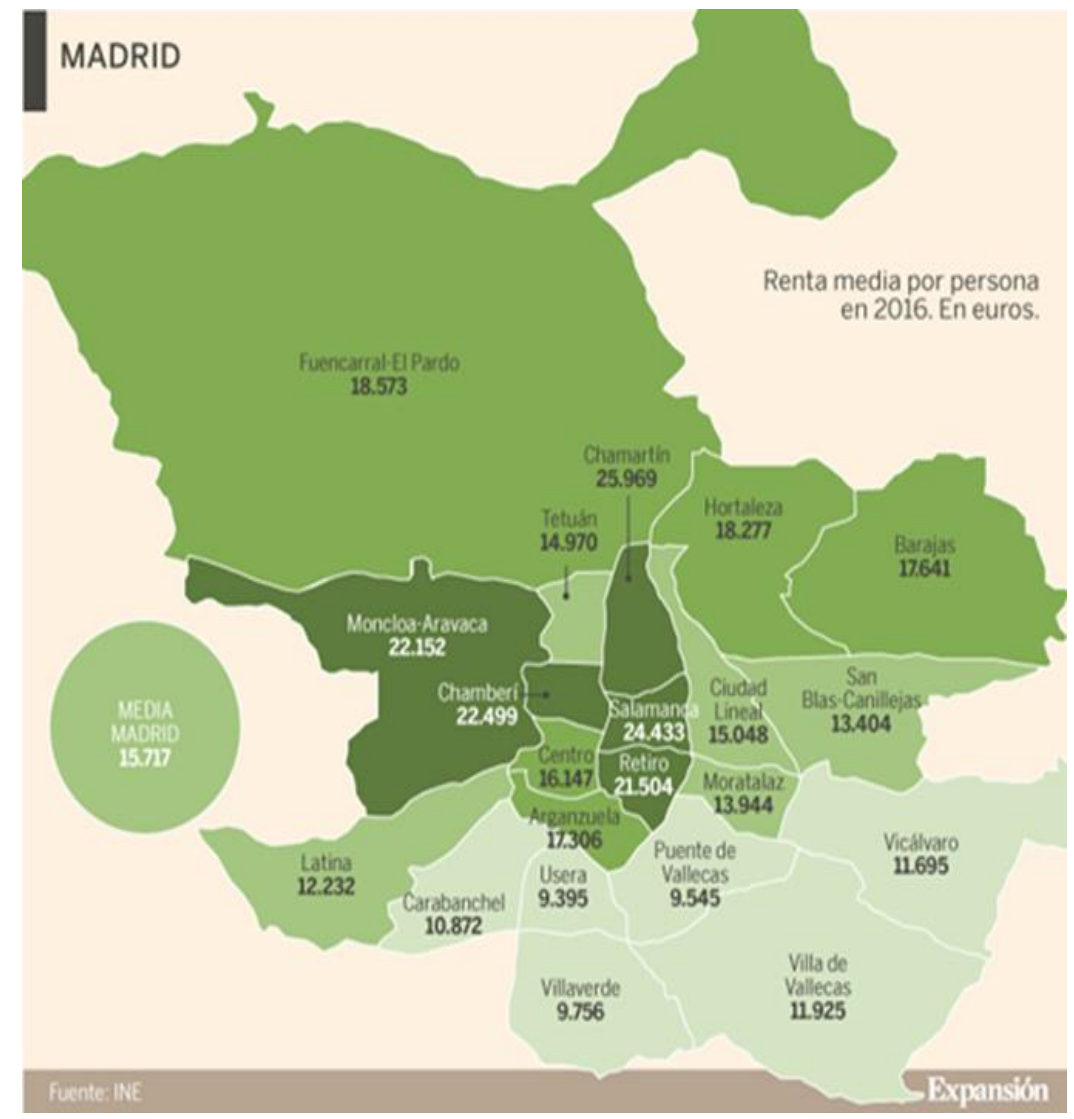

Figura 3 Distribución de las rentas en los distritos de Madrid (Fuente Expansion.com, Madrid: Así se distribuye la renta por distritos. Disponible en:

https://www.expansion.com/economia/2019/09/12/5d7a1c78e5fdea4b218b458e.html)

Tabla VI Ranking de vulnerabilidad por distritos en el año 2020 [37]

\begin{tabular}{|c|c|c|}
\hline Ranking & Distrito & Índice de vulnerabilidad \\
\hline 1 & Puente de Vallecas & 0,01103279 \\
\hline 2 & Villaverde & 0,01020985 \\
\hline 3 & Usera & 0,01011839 \\
\hline 4 & Carabanchel & 0,0095895 \\
\hline 5 & Latina & 0,00857847 \\
\hline 6 & Villa de Vallecas & 0,00881781 \\
\hline 7 & San Blas & 0,00832844 \\
\hline 8 & Tetuán & 0,00800222 \\
\hline 9 & Moratalaz & 0,00792162 \\
\hline 10 & Vicálvaro & 0,0080996 \\
\hline
\end{tabular}


El incide de vulnerabilidad mide varios parámetros:

- Vulnerabilidad de la población en base al porcentaje de:

- Inmigrantes.

- Esperanza de vida.

- Sin estudios o Primarios.

- Estatus socio económico en relación con el porcentaje de la renta media del hogar.

- Actividad económica en relación con el porcentaje de:

- Tasa de paro.

- Tasa de paro en mayores de 45 años.

- Tasa de parados sin prestación.

- Desarrollo urbanístico en relación con el porcentaje del valor catastral.

- Necesidades asistenciales en relación con el porcentaje de:

- Tasa de demanda dependientes.

- Familias perceptoras de renta mínima.

- Tasa SAD (servicio de ayuda a domicilio) dependencia.

- Tasa de teleasistencia a la dependencia.

Para obtener visión comparativa en la siguiente Tabla VII comparativa observamos la grieta de desigualdad existente entre San Cristóbal el barrio más vulnerable de Madrid y El Viso el barrio menos vulnerable de Madrid teniendo en cuenta los parámetros en los que se basa el índice de vulnerabilidad.

Tabla VII Tabla comparativa del distrito más vulnerable con el menos vulnerable de Madrid en el año 2020 [37]

\begin{tabular}{|c|c|c|c|}
\hline \multirow[t]{2}{*}{$\begin{array}{l}\text { Ranking de } \\
\text { vulnerabilidad }\end{array}$} & Barrio (Distrito) & $\begin{array}{c}\text { SAN CRISTÓBAL } \\
\text { (Villaverde) }\end{array}$ & $\begin{array}{c}\text { EL VISO } \\
\text { (Chamartín) }\end{array}$ \\
\hline & Puesto del ranking & 1 & 131 \\
\hline \multirow{3}{*}{ Población } & Tasa de extranjeros & 29,07 & 6,20 \\
\hline & Esperanza de vida & 82,19 & 86,4 \\
\hline & Sin estudios o primarios & 73,84 & 16,05 \\
\hline $\begin{array}{l}\text { Estatus } \\
\text { socioeconómico }\end{array}$ & Renta media hogar & 19859 & 88194 \\
\hline \multirow{3}{*}{$\begin{array}{l}\text { Actividad } \\
\text { económica. }\end{array}$} & Tasa Paro Absoluto & 13,33 & 3,06 \\
\hline & Tasa Paro mayores 45 & 16,84 & 4,28 \\
\hline & $\begin{array}{l}\text { Tasa de Parados Sin } \\
\text { Prestación }\end{array}$ & 6,82 & 2,51 \\
\hline $\begin{array}{l}\text { Desarrollo } \\
\text { Urbanístico }\end{array}$ & Valor Catastral & $26.918 €$ & $312.996 €$ \\
\hline \multirow{2}{*}{$\begin{array}{l}\text { Necesidades } \\
\text { Asistenciales }\end{array}$} & $\begin{array}{l}\text { Tasa demanda } \\
\text { Dependientes }\end{array}$ & $5,00 \%$ & $1,9 \%$ \\
\hline & $\begin{array}{l}\text { Familas perceptoras renta } \\
\text { mínima }\end{array}$ & 1.625 & 148 \\
\hline \multicolumn{2}{|c|}{ Tasa SAD Dependencia } & $6,40 \%$ & $1,5 \%$ \\
\hline \multicolumn{2}{|c|}{ Tasa Teleasistencia Dependencia } & $7,20 \%$ & $2,6 \%$ \\
\hline \multicolumn{2}{|l|}{ Población } & 0,01742 & 0,00436 \\
\hline \multicolumn{2}{|c|}{ Estatus Socio-Económico } & 0,00766 & 0,00757 \\
\hline \multicolumn{2}{|c|}{ Actividad Económica } & 0,01355 & 0,00393 \\
\hline \multicolumn{2}{|l|}{ Desarrollo Urbano } & 0,00768 & 0,00751 \\
\hline
\end{tabular}




\begin{tabular}{|l|c|c|}
\hline Necesidades Asistenciales & 0,01314 & 0,00244 \\
\hline Vulnerabilidad & $\mathbf{0 , 0 1 1 8}$ & $\mathbf{0 , 0 0 5 3}$ \\
\hline
\end{tabular}
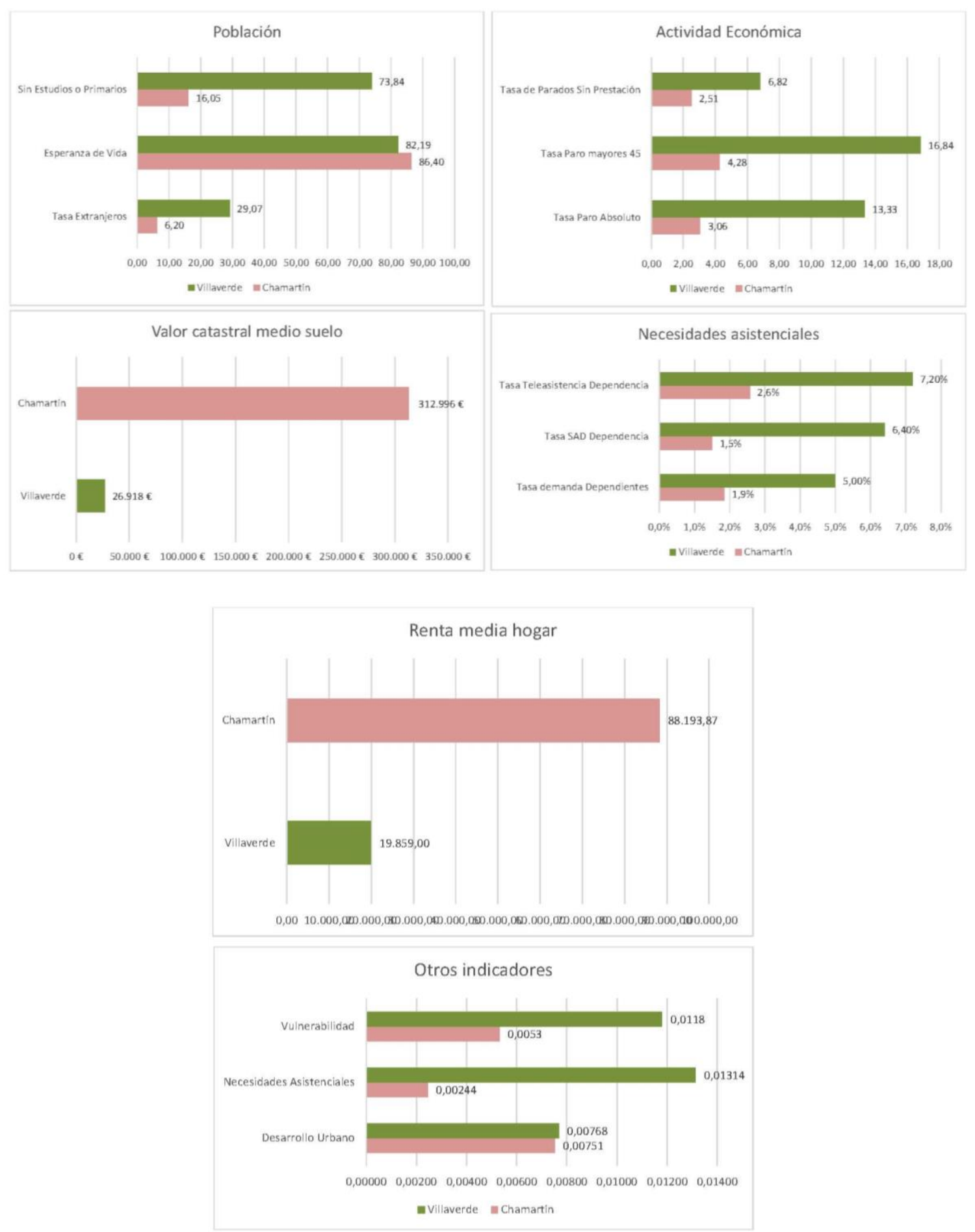

Figura 4 Gráficas comparativas del distrito más vulnerable con el menos vulnerable de Madrid en el año 2020

Si nos centramos en los principales distritos de la ciudad de Madrid habitados por las supervivientes, el ranking de vulnerabilidad se caracteriza por lo expuesto en la Tabla 3.2.3.3. [37]. 
Tabla VIII Modelo índice Vulnerabilidad aplicado al Proceso Analítico Jerárquico [37]

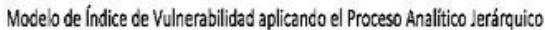

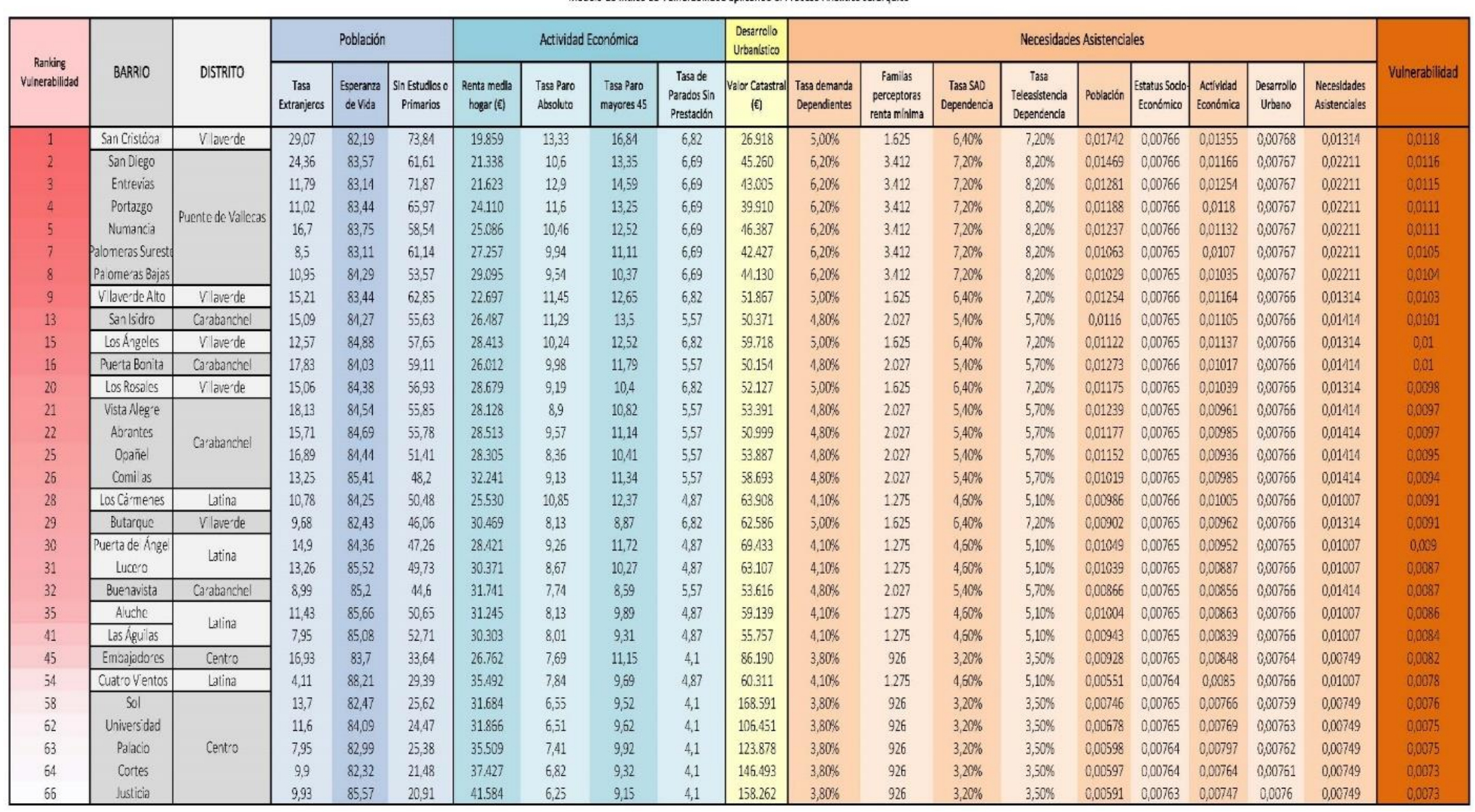




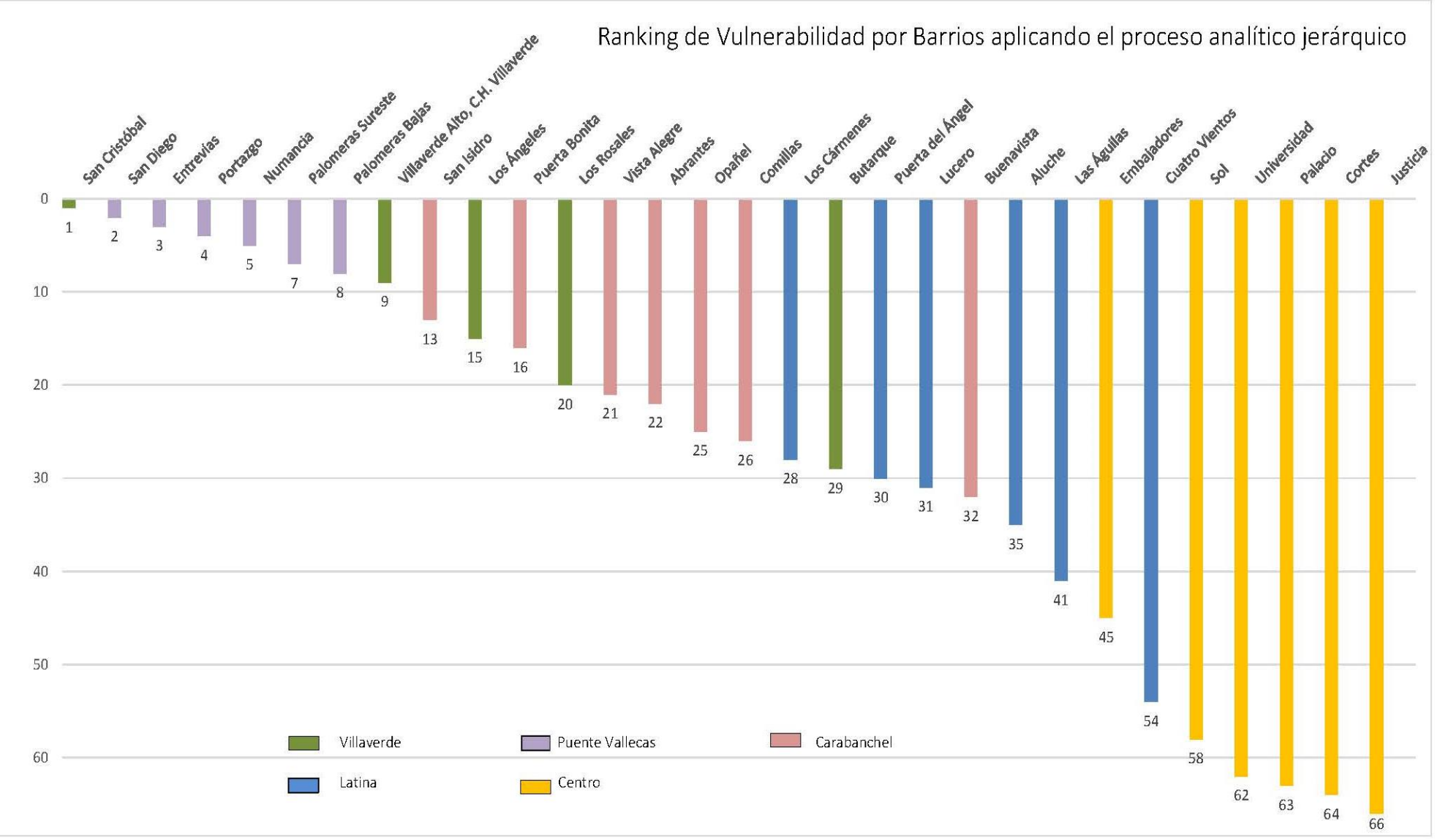

Figura 5 Ranking de vulnerabilidad por barrios aplicando el proceso analítico jerárquico 
Asimismo, suelen vivir en condiciones guetarías, ya que les supone menos coste económico. Estas viviendas son compartidas con personas de su mismo origen o condición, es decir que aunque viven en comunidad, las condiciones son de hacinamiento en pisos pequeños incluso compartiendo varias familias una habitación o el concepto de "cama caliente" (una persona duerme por el día y otra por la noche), asimismo cumplen rasgos de exclusión social como vivir en condiciones insalubres, no tener acceso a la tarjera sanitaria o la analfabetización de los menores sin papeles.

Si hablamos de la esfera cultural, la MGF es aceptada en su cultura y sociedad de origen pero no en nuestro país, ya que es un hecho penado por la ley.

Finalmente, a nivel sanitario, son mujeres que debido a la mutilación sufren secuelas de por vida como dolor, infecciones de repetición, pérdidas de orina, sentimientos de ambivalencia, rechazo miedo y/o fobia, patologías que precisan numerosas consultas médicas y psicológicas. Además al conocer la magnitud del problema sienten vergüenza, se aíslan y de nuevo sufren exclusión social, dificultando aún más la regularización de los papeles, el acceso a un trabajo digno que les permita cotizar en la seguridad social y disponer de servicios gratuitos como son la sanidad o la escolarización de sus hijos, por ello no pueden cubrir sus necesidades básicas de la vida diaria ni las de su prole, convirtiéndose en un problema individual, familiar, comunitario y social, recordemos que a nivel global 200 millones de mujeres han sido sometidas en la actualidad.

\subsubsection{Aspectos culturales de la MGF de las supervivientes que viven en la Comunidad de Madrid}

Las causas que manifiestan la continuación de la práctica de la MGF se fundamentan en las estructuras socioculturales de las sociedades practicantes de origen, por ello, no son propias de la Comunidad de Madrid [38].

Como recordatorio decir que, se trata de una tradición religiosa y/o cultural que concede identidad de género y de etnia a las mujeres/niñas. Se ejecuta creyendo que facilita la preservación de la virginidad, fomenta la fidelidad e incrementa las posibilidades nupciales y también está relacionado con los cánones de belleza e higiénicos.

\subsubsection{Acogida.}

En 2013 [2] se constituyó “La Red de Prevención de Mutilación Genital Femenina”, con la ayuda de la Consejería de Sanidad, SERMAS, Madrid Salud, Ayuntamiento de Madrid, Ayuntamiento de Parla, Médicos del Mundo, Asociación Madrileña de Pediatría de Atención Primaria, Sociedad Madrileña de Medicina de Familia y Comunitaria, Asociación Madrileña de Salud Pública, Asociación de Matronas de Madrid, UNAF, Safe a Girl Safe a Generation, Sexólogos Sin Fronteras, lasexología.com y la Federación de mujeres progresistas. La finalidad de esta red es aportar una asistencia biopsicosocial a las mujeres supervivientes, mediante la coordinación de actuaciones orientadas a mejorar la prevención de la MGF y la asistencia que reciben estas mujeres. Actualmente están en vigor la "Guía de Actuaciones Sanitarias para la Prevención de la Mutilación Genital Femenina en la Comunidad de Madrid", publicada en 2017 [2], mediante la que trabajan de forma coordinada todos los profesionales y organizaciones competentes, abordando temas de suma importancia que se agrupan en varios apartados:

- Perspectiva comunitaria.

- Intervención con las mujeres procedentes de países/etnias que practican la MGF.

- Asistencia en la gestación, parto y puerperio.

- Actuación con los hombres.

- Coordinación y registro de las actividades y resultados obtenidos. 


\section{Resultados y discusión.}

La MGF es un tema candente desde los años 70, con un aumento en el número de apariciones de su forma de expresión "MGF", "FGM" (traducción al inglés de la MGF), sunna, ablación, corte, circuncisión, aunque finalmente se concluyó que la terminología adecuada es Mutilación Genital femenina, porque engloba los diferentes tipos de mutilación.

La tendencia al alza para hablar se produjo gracias al trabajo de activistas y al movimiento feminista desde los años 70, 80 en adelante. En primer lugar, se impugnó la equiparación de la circuncisión masculina con la MGF, por varios motivos:

- Los estudios científicos demostraron que la MGF es una forma de control de la capacidad reproductiva y la sexualidad de la mujer, mientras que la circuncisión masculina no.

- Esta práctica señala aún más los roles sociales de cada género, porque al extirpar el clítoris, en muchas culturas se considera que se elimina la parte masculina, fomentándose el dominio social de la mujer, favorecido por el dolor y la violación de su integridad física.

- Sobre los ritos de institución, la MGF legitima la diferencia hombre-mujer, sustentado por las relaciones desiguales de poder.

A finales del siglo veinte el discurso político a nivel global manifiesta que, la MGF es una forma de violación de los derechos humanos de la mujer, suponiendo un problema global que no solo afecta a las mujeres de origen africano sino a pequeños pueblos del sur de América, también a Asia Oriental y es una práctica extendida reconocida recientemente en países como Indonesia.

Actualmente en España, cualquier tipo de práctica relacionada con la mutilación genital femenina supone delito y queda constancia de ello en el "artículo 149.2 de la Ley Orgánica 10/1995, de 23 de noviembre, del Código Penal (modificada por la Ley Orgánica 11/2003)" [38].

La actuación de la Comunidad de Madrid y la acogida a las supervivientes o mujeres en riesgo de sufrir este tipo de violencia, se considera junto con País Vasco una de las comunidades con más poder reivindicativo y protector de los derechos de estas personas, comenzando por la protección sanitaria de esa mujer, que se extiende tanto en atención hospitalaria como primaria, mediante la "Guía De Actuaciones Sanitarias Para La Prevención De La Mutilación Genital Femenina En La Comunidad De Madrid" siendo el profesional el que deja constancia de que la mujer que está en riesgo de ser mutilada o ha sido superviviente, para posteriormente brindarle protección o realizar un seguimiento de las complicaciones y así, poder derivarla al profesional indicado (urólogo, ginecólogo, pediatra, psicólogo, sexólogo, etc.), considerándose también una posible cirugía reconstructiva en el caso de la infibulación. Asimismo, la Comunidad de Madrid con el apoyo de la Consejería de Sanidad en el 2019 formó cerca de 740 sanitarios en la prevención y tratamiento de este tipo de violencia de género. Además, del apoyo sanitario, estas personas reciben soporte social gracias a los equipos multidisciplinares que se encuentran en los servicios sanitarios y sociales compuestos por psicólogos, trabajadores y educadores sociales, junto con la actuación de las mediadoras que trabajan a través de ONG como Médicos del Mundo o asociaciones como UNAF. Paralelamente, la Consejería de Sanidad de la Comunidad Madrid, en la "Comisión Técnica de Acciones en Salud frente a la Violencia de Género" (CTVG), ha desarrollado diferentes intervenciones, participando activamente en la "Red de Prevención de la Mutilación Genital Femenina en la Comunidad de Madrid" y promoviendo la formación y empoderamiento social en aquellos distritos con mayor agrupación de mujeres víctimas o en riesgo de padecer MGF, como es el ejemplo de la celebración del "Día Internacional de Tolerancia 0 con la MFG", en el cual se organizan mesas informativas en el distrito de Villaverde que rotan por los centros de salud y el Hospital 12 de Octubre por ser los centros que atienden a más personas de países donde se practica la MGF. No obstante, aún quedan descubiertos puntos de suma importancia como por ejemplo es el desarrollo psicoafectivo y sexual de estas mujeres siendo uno de los puntos débiles que la Comunidad de Madrid aún no ha incluido en la "Guía De Actuaciones Sanitarias Para La Prevención De La Mutilación Genital Femenina En La Comunidad De Madrid". 
Con respecto a la salud sexual de la superviviente o la mujer en riesgo de poder este tipo de violencia. La práctica de la MGF asienta la posición del poder patriarcal, asegurando el control corporal y la sexualidad de las mujeres, mediante la sustentación de mandatos de género como la virginidad, pureza o la anulación del deseo sexual. En líneas generales, se defienden los derechos de menores y mujeres, pero el derecho a que la superviviente logre una sexualidad saludable es un aspecto controvertido. Actualmente se dispone de pocos estudios con resultados fiables porque es reciente el conocimiento que se tienes de la MGF sobre la salud sexual. Además la sexualidad varía en cada mujer y en cada etapa de su vida, asimismo la función sexual es compleja de evaluar, pero como agravante encontramos que los resultados han sido modificados por la norma social y los estereotipos, por ello aún no existe un acuerdo sobre qué herramienta se debe usar para medir la esfera sexual de estas mujeres. Siendo la salud sexual de las supervivientes, otro reto futuro a plantear. Particularmente, las personas migrantes residentes en nuestro país, pueden acceder a más recursos y derechos como por ejemplo el "Derechos Sexuales y Reproductivos, como Derechos Humanos Internacionales", pero para ello es necesario facilitar la acogida eliminando las trabas burocráticas y administrativas, el desconocimiento, la barrera idiomática, la clave cultural, los prejuicios o ideas preconcebidas, ya que suponen una barrera para acceder a la educación sexual desde los soportes sociales, sanitarios y educativos.

Por último, cabe destacar que los objetivos futuros se centran en el cambio social que es un camino lento, pero que a escala global el fenómeno está vinculado a la circulación de personas e ideas, por ello se debe tener en cuenta las políticas, creencias y culturas tanto países de llegada como en los de origen, siendo desfavorable infravalorar la metamorfosis social de las poblaciones implicadas, obviar la asimetría de mandato Norte-Sur en la actuación internacional para erradicar esta práctica, por ello, debemos actuar en base a los testimonios, experiencias y percepciones, de las mujeres implicadas, con el objetivo de empoderarlas y aportarles las herramientas necesarias para ser supervivientes sanas e independientes, siendo ellas mismas la semilla del cambio en su comunidad.

\section{Conclusiones}

La justicia mundial condena la MGF por violar los derechos de la mujer, al fomentar la participación desigual en la sociedad, mediante el control de su fecundidad y la sexualidad, la imposición de cánones de género denigrantes, la discriminación y la existencia de secuelas tanto psicológicas como físicas a largo plazo.

Se ha observado que el año de adhesión de una ley en contra de la MGF y la opinión social son las herramientas más importantes para erradicar este tipo de práctica.

A nivel de la Comunidad de Madrid se observa que las supervivientes y/o mujeres en riesgo de sufrir MGF se aglutina en distritos que del ranking de vulnerabilidad en el año 2020, donde el metro cuadrado de la vivienda es más barato y las renta son más bajas (menos de 10.000 euros). Lo cual corrobora una situación de vida precaria tanto de la mujer como de su familia, hecho que corrobora que la MGF es un problema de social.

Con respecto a la acogida que brinda la Comunidad de Madrid, es de carácter optimo a nivel socio sanitario, dando especial importancia a la esfera gineco-obstétrica de la mujer, pero dejando totalmente de lado el bienestar sexual de la misma, conociendo que la sumisión y anulación sexual es otra forma más de violencia hacia la mujer mutilada. 
Conflictos de Intereses: Las autoras no declaran conflicto de intereses.

\section{Abreviaturas}

Las siguientes abreviaturas son usadas en este manuscrito:

A/MGF: Ablación/Mutilación Genital Femenina.

AEGO: Asociación española de ginecología y obstetricia.

CEDAW: Convention on the Elimination of All Forms of Discrimination against Women ("Convención sobre la Eliminación de Todas las Formas de Discriminación contra la Mujer" Traducción al Castellano)

EEUU: Estados Unidos

FIGO: Federación Internacional de Ginecología y Obstetricia.

FGM: Female Genital Mutilation.

FGM/C: Female Genital Mutilation/Cutting.

FNUAP: Fondo de Población de las Naciones Unidas (Siglas en inglés - United Nations Population Fund.

HGUGM: Hospital General Universitario Gregorio Marañón.

ITS: Infección de transmisión sexual

ITU: Infección del tracto urinario.

MGF: Mutilación Genital Femenina.

ONG: Organización No Gubernamental.

OMS: Organización Mundial de la Salud.

ONU: Organización de las Naciones Unidas.

SemFYC: Sociedad Española de Medicina de Familia y Comunitaria.

TFM: Trabajo fin de máster.

UE: Unión Europea.

UK: United Kingdom

UN: United Nations

UNAF: Unión De Asociaciones Familiares.

WHO: World Health Organization.

\section{Referencias bibliográficas}

1. UAB: Universidad Autónoma de Barcelona. Más de 3.600 niñas están en peligro de sufrir la mutilación genital femenina en España (internet). Barcelona: UAB; 13 nov 2020 (2021, citado 10 marzo 2021) Disponible en: https://www.uab.cat/web/sala-de-prensa/detalle-noticia/mas-de-3-600-ninas-estan-en-peligro-desufrir-la-mutilacion-genital-femenina-en-espana-1345667994339.html?noticiaid=1345829215799

2. García de Herreros Madueño, T., Garabato González, S., Martínez Blanco, M.L. (coords.) y Grupo de Trabajo. Guía de actuaciones sanitarias para la prevención de la Mutilación Genital Femenina en la Comunidad de Madrid (internet). Madrid: Red de Prevención de la Mutilación Genital Femenina en la Comunidad de Madrid; 2017 (citado 10 marzo 2021) Disponible en: https://www.madrid.es/UnidadesDescentralizadas/IgualdadDeOportunidades/Publicaciones/Mutilaci\%C 3\%B3n\%20genital\%20femenina/Guia_actuaciones_sanitarias_MGF.pdf

3. OMS: Organización Mundial de la Salud. Mutilación genital femenina. Salud sexual y reproductiva. Temas de salud sexual y reproductiva (internet). Suiza: HRP; 2020 (2021, citado 10 marzo 2021) Disponible en: https://www.who.int/reproductivehealth/topics/fgm/es/\#: :text=La\%20mutilaci\%C3\%B3n\%20genital\%20f emenina $\% 20$ (MGF,femeninos\%20por\%20motivos\%20no\%20m\%C3\%A9dicos

4. European women's lobby europeen des femmes. Campaña europea END FGM: Amnistía Internacional lanza un nuevo video para conmemorar el día internacional de tolerancia cero con la mutilación genital femenina Amnesty International Irelan (internet). Belgica: EWL; 7 feb 2013 (2021, citado 10 marzo 2021). Disponible en: https://www.womenlobby.org/END-FGM-European-Campaign-Amnesty-Internationalreleases-new-video-to-mark?lang=en

5. Nawal N.M. Corte genital femenino (circuncisión) (internet). UpToDate; 1 sep 2020. (2021, citado 10 marzo 2021). Disponible en: https://www-uptodate-com.bvcscm.a17.csinet.es/contents/female-genital-cuttingcircumcision?search=mutilaci $\% C 3 \%$ B3n $\% 20$ genital $\% 20$ femenina\&source=search_result\&selectedTitle=1 2 7\&usage_type=default\&display_rank=1 
6. UNFPA: Fondo de Población de las Naciones Unidas. Cuando los trabajadores sanitarios hacen daño: la medicalización de la mutilación genital femenina en Egipto (internet). EEUU: UNFPA; 2 oct 2019 (2020, citado 10 marzo 2021). Disponible en: https://www.unfpa.org/es/news/cuando-los-trabajadoressanitarios-hacen-da\%C3\%B1o-la-medicalizaci\%C3\%B3n-de-la-mutilaci\%C3\%B3n-genital

7. Instituto de Estadística. Padrón Continuo [base de datos en Internet]. Madrid: Comunidad de Madrid; 2015 (2021, citado 10 marzo 2021). Disponible en: http://www.madrid.org/iestadis/

8. Hedley, R, Dorkenoo, E. Consejos sobre protección infantil y mutilación genital femenina para profesionales sanitarios, educativos y sociales. Londres: ADELANTE, 1992.

9. Hosken, RP. Informe Hosken Mutilación sexual y genital de mujeres. Lexington: Women International Network News, 1994.

10. Morgan J. Trabajando para poner fin a la MGF. Reino Unido: Lancet, 2015.

11. González Henao, R. La Ablación Genital Femenina En Comunidades Emberá Chamí. Scielo (internet). Julio 2011 (11 marzo 2021) Cad. Pagu (37). Disponible en: http://www.scielo.br/scielo.php?script=sci_arttext\&pid=S0104-83332011000200006

12. Kaplan, A. et cols .Diagnóstico mutilación genital femenina en la comunidad autónoma de Euskadi. Informe 35. Pais vasco: (EMAKUNDE) Instituto Vasco de la Mujer; 2014 (2016, 11 marzo 2021). Disponible en:

https://www.euskadi.eus/contenidos/informacion/publicaciones_informes/es_emakunde/adjuntos/inform e.35.diagnostico_mgf_cae.pdf

13. AEGO: Asociación Española de Ginecología y Obstetricia. Mutilación Genital Femenina (internet). Madrid: AEGO; 2020 (2021, citado 10 marzo 2021). Disponible en: https://www.aego.es/otrainformacion/mutilacion-genital-femenina. Consultado el 2 de Octubre del 2020.

14. Rodríguez Pecino, B. Tipos de mutilación genital femenina; Blog: mujer (internet). Madrid: Ayuda en Acción; 7 en 2020 (2020, citado 10 marzo 2021). Disponible en: https://ayudaenaccion.org/ong/blog/mujer/tipos-mutilacion-genital-femenina/

15. OMS: Organización Mundial de la Salud. Mutilación genital femenina. (internet). Suiza: OMS; 3 feb 2012 (2021, citado marzo 11 2021). Disponible en: http://www.who.int/mediacentre/factsheets/fs241/es/index.html

16. OMS: Organización Mundial de la Salud; UNFPA: Fondo de Población de las Naciones Unidas y UNICEF: el Fondo de las Naciones Unidas para la Infancia. Mutilación genital femenina: declaración conjunta OMS / UNICEF / UNFPA (internet). Ginebra (IRIS): Intitutional Repository for information sharing; 1997 (2020, citado marzo 2020) Disponible en: https://apps.who.int/iris/bitstream/handle/10665/41903/9241561866.pdf?sequence=1\&isAllowed=y

17. AMM: Asociación Médica Mundial. Declaración de la AMM sobre la Mutilación Genital Femenina (internet).Francia: AMM; 23 mar 2017 (2020, citado 11 marzo 2021). Disponible en: https://www.wma.net/es/policies-post/declaracion-de-la-amm-sobre-la-mutilacion-genital-femenina/.

18. UNICEF: el Fondo de las Naciones Unidas para la Infancia Female Genital Mutilation/Cutting: A statistical overview and exploration of the dynamics of change (internet) UNICEF; jun 2013 (2021, 11 marzo 2021) Disponible en: https://data.unicef.org/resources/fgm-statistical-overview-and-dynamics-of-change/

19. Dirie MA, Lindmark G. El riesgo de complicaciones médicas después de la circuncisión femenina. East Afr Med J 1992; 69: 479.

20. Ozumba BC. Gynetresia adquirida en el este de Nigeria. Int J Gynaecol Obstet 1992; 37: 105.

21. Agugua NE, Egwuatu VE. Circuncisión femenina: manejo de complicaciones urinarias. J Trop Pediatr 1982; 28: 248 .

22. Nour NM. Cálculo urinario asociado con la incisión genital femenina. Obstet Gynecol 2006; $107: 521$. Consultado el 2 de Octubre del 2020.

23. Toubia N. La circuncisión femenina como problema de salud pública. N Engl J Med 1994; 331: 712.

24. Fernández-Aguilar S, Noël JC. Neuroma del clítoris después de la ablación genital femenina. Obstet Gynecol 2003; 101: 1053.

25. Banks E, Meirik O, et al (Grupo de estudio de la OMS sobre mutilación genital femenina y resultado obstétrico) Mutilación genital femenina y resultado obstétrico: estudio prospectivo colaborativo de la OMS en seis países africanos. Lancet. 2006; 367: 1835.

26. Macleod, T. Mutilación genital femenina. J SOGC 1995; 4: 333.

27. De Silva S. Secuelas obstétricas de la circuncisión femenina. Eur J Obstet Gynecol Reprod Biol 1989; $32: 233$. 
28. ACOG: Colegio Americano de Obstetras y Ginecólogos. Circuncisión femenina / Mutilación genital femenina: manejo clínico de mujeres circuncisas. Colegio Americano de Obstetras y Ginecólogos, Washington, DC 1999.

29. Andersson SH, Rymer J, Joyce DW y col. Calidad de vida sexual en mujeres que han sufrido mutilación genital femenina: un estudio de casos y controles. BJOG 2012; 119: 1606.

30. Okonofu FE, Larsen U, Oronsaye F, et al. La asociación entre la ablación genital femenina y los correlatos de morbilidad sexual y ginecológica en el estado de Edo, Nigeria. BJOG 2002; 109: 1089.

31. Thabet SM, Thabet AS. Sexualidad defectuosa y circuncisión femenina: la causa y el posible manejo. J Obstet Gynaecol Res 2003; 29:12.

32. Jiménez García, A. Granados Bolivar M.E. Impacto bio-psicológico en mujeres sometidas a mutilación genital. Scielo (internet) $2016 \quad$ (11 marzo 2021). $10 \quad$ (1). Disponible en: http://scielo.isciii.es/scielo.php?script=sci_arttext\&pid=S1988-348X2016000100003.

33. Epdata. La mutilación genital femenina en el mundo, en datos y gráficos (internet). Madrid: Europa; 5 feb 2021 (2021, 11 marzo 2021). Disponible en: https://www.epdata.es/datos/mutilacion-genital-femeninamundo-datos-mapas-graficos/293.

34. Ley 5/2005, de 20 de diciembre, Integral contra la Violencia de Género de la. Articulo 7.4 y 29. Legislación de la Comunidad de Madrid. BOCM. Publicada el 20 de Diciembre del 2005. Página actualizada el 4 de Agosto del 2020. Disponible en: http://www.madrid.org/wleg_pub/secure/normativas/contenidoNormativa.jsf?opcion=VerHtml\&nmnor ma $=3351 \&$ cdestado=P\#no-back-button .

35. Comunidad de Madrid. Día Internacional de Tolerancia Cero con la Mutilación Genital Femenina (internet). Madrid: Comunidad de Madrid Noticias; 5 feb 2020 (2021, 11 marzo 2021). Disponible en: https://www.comunidad.madrid/noticias/2020/02/05/dia-internacional-tolerancia-cero-mutilacion-genitalfemenina

36. INE: Instituto de Estadística. Padrón Continuo [base de datos en Internet]. Madrid: Comunidad de Madrid; 2015 (2021, 11 marzo 2021). Disponible en: http://www.madrid.org/iestadis/.

37. Datos abiertos. Ranking de vulnerabilidad distritos (internet). Madrid: Ayuntamiento de Madrid. 2020 (2020,
11
marzo
2021).
Disponible
en: https://datos.madrid.es/portal/site/egob/menuitem.c05c1f754a33a9fbe4b2e4b284f1a5a0/?vgnextoid=d029e d1e80d38610VgnVCM2000001f4a900aRCRD\&vgnextchannel=374512b9ace9f310VgnVCM100000171f5a0a RCRD\&vgnextfmt=default

38. Nuño Gómez, L. Kaplan Marcusán, A. Aspectos Socioculturales y Legales de la Mutilación Genital Femenina: Experiencias Transnacionales De Prevención Y Protección Actas del Congreso Internacional. Celebrado en Madrid, 3 y 4 de febrero 2017. Disponible en: https://mgf.uab.cat/esp/images/news_media/news/images/Noticia9_AnexoEspa\%C3\%B1ol.pdf 